Article

\title{
Iron and Aluminium Production Wastes as Exclusive Components of Alkali Activated Binders-Towards a Sustainable Alternative
}

\author{
Nuno Cristelo ${ }^{1, *(\mathbb{D})}$, Fernando Castro ${ }^{2}\left(\mathbb{D}\right.$, Tiago Miranda ${ }^{3}$, Zahra Abdollahnejad ${ }^{4}$ and Ana Fernández-Jiménez ${ }^{5}(\mathbb{D}$ \\ 1 CQ-VR, Department of Engineering, University of Trás-os-Montes e Alto Douro, 5000-801 Vila Real, Portugal \\ 2 Metrics, Department of Mechanical Engineering, University of Minho, Campus de Azurém, \\ 4800-058 Guimarães, Portugal; fcastro@dem.uminho.pt \\ 3 ISISE, School of Engineering, University of Minho, Campus de Azurém, 4800-058 Guimarães, Portugal; \\ tmiranda@civil.uminho.com \\ 4 Department of Civil and Environmental Engineering, University of Connecticut, Mansfield, CT 06269, USA; \\ Zahra.abdollahnejad@uconn.edu \\ 5 Eduardo Torroja Institute for Construction Science (IETcc-C.S.I.C.), E28033 Madrid, Spain; anafj@ietcc.csic.es \\ * Correspondence: ncristel@utad.pt
}

check for updates

Citation: Cristelo, N.; Castro, F.; Miranda, T.; Abdollahnejad, Z.; Fernández-Jiménez, A. Iron and Aluminium Production Wastes as Exclusive Components of Alkali Activated Binders-Towards a Sustainable Alternative. Sustainability 2021, 13, 9938. https://doi.org/ $10.3390 /$ su13179938

Academic Editors: Jorge de Brito and Miguel Bravo

Received: 29 June 2021

Accepted: 31 August 2021

Published: 4 September 2021

Publisher's Note: MDPI stays neutral with regard to jurisdictional claims in published maps and institutional affiliations.

Copyright: (c) 2021 by the authors. Licensee MDPI, Basel, Switzerland. This article is an open access article distributed under the terms and conditions of the Creative Commons Attribution (CC BY) license (https:// creativecommons.org/licenses/by/ $4.0 /)$.
Abstract: The sustainability of resources is becoming a worldwide concern, including construction and building materials, especially with the alarming increase rate in global population. Alternative solutions to ordinary Portland cement (OPC) as a concrete binder are being studied, namely the so-called alkali-activated cements (AAC). These are less harmful to the environment, as lower $\mathrm{CO}_{2}$ emissions are associated with their fabrication, and their mechanical properties can be similar to those of the OPC. The aim of developing alkali-activated materials (AAM) is the maximization of the incorporated recycled materials, which minimises the $\mathrm{CO}_{2}$ emissions and cost, while also achieving acceptable properties for construction applications. Therefore, various efforts are being made to produce sustainable construction materials based on different sources and raw materials. Recently, significant attention has been raised from the by-products of the steelmaking industry, mostly due to their widespread availability. In this paper, ladle slag (LS) resulting from steelmaking operations was studied as the main precursor to produce AAC, combined with phosphating bath sludge — or phosphate sludge (PS) — and aluminium anodising sludge (AS), two by-products of the surface treatment of metals, in replacement rates of 10 and $20 \mathrm{wt} . \%$. The precursors were activated by two different alkaline solutions: a combination of commercial sodium hydroxide and sodium silicate (COM), and a disposed solution from the cleaning of aluminium extrusion steel dies (CLE). This study assesses the influence of these by-products from the steelmaking industry (PS, AS and CLE) on the performance of the alkali-activated LS, and specifically on its fresh and hardened state properties, including rheology, heat of hydration, compressive strength and microstructure and mineralogy (X-ray diffraction, scanning electron microscopy coupled with energy dispersive spectroscopy and Fourier transform infra-red. The results showed that the CLE had no negative impact on the strength of the AAM incorporating PS or/and AS, while increasing the strength of the LS alone by $2 \times$. Additionally, regardless of the precursor combination, the use of a commercial activator (COM) led to more fluid pastes, compared with the CLE.

Keywords: phosphate sludge; aluminium anodizing sludge; ladle slag; alkali activated materials; sustainability

\section{Introduction}

Globally, there is an increasing concern regarding the sustainability of the planet's natural resources. The United Nations have set 17 sustainability goals, including sustainable industrialisation, to increase the use of the current resources to their maximum extent and encompass newer and cleaner technologies by 2030 [1]. Research is thus being conducted to 
alleviate the strain on resources, including the discovery of new raw materials for concrete, especially those based on wastes and residues.

Concrete is fabricated globally with ordinary Portland cement (OPC), due to the wellknown secular mechanical strength and durability it can provide. However, the production of OPC is a highly intense process, which includes a calcination step with temperatures up to $1500{ }^{\circ} \mathrm{C}$, resulting in significant carbon dioxide $\left(\mathrm{CO}_{2}\right)$ emissions and, consequently, a very harmful environmental impact [2,3]. Partial replacements of OPC with industrial wastes are common practice nowadays $[4,5]$, using, for instance, ground granulated blast-furnace slag [6], coal fly ash [7], ladle slag [8,9], ceramic waste [10], among others.

The production of OPC is expensive, both in economic and environmental terms. The cost associated with the construction and operation of an industrial unit devoted to the fabrication of cement could be considerably reduced if alkali activation technology is preferred. Alkali activated cements (AAC), as the newest generation of green concrete, are the latest result of a long list of studies targeting the development of alternatives to OPC. Regardless of its many possible origins (and AAC can indeed be produced from a wide range of raw materials, most of it are wastes), the majority of the AAC reported in the literature showed excellent or, at least, above-average mechanical and durability performances. In addition to minimising the consumption of OPC, this 'green' binder also favours the consumption of industrial wastes, offering significant environmental benefits [11,12].

Alkali-activated binders can be used as eco-friendly alternative materials, with competitive mechanical and durability properties, in comparison to Portland cement [13]. While developing alkali activated materials, the aim is usually the maximization of the waste content, while also generating cost effective and sustainable alternatives for the construction industry. Several studies showed that the capacity to incorporate industrial by-products, at such significant scales, introduces environmental advantages and cost-effective solutions in the construction industry $[14,15]$. However, it is important to notice that both fresh and hardened state properties of AAC are significantly complicated to assess and predict, especially due to the different parameters controlling the several phases of the reaction, as well as the outcome of the curing period.

Annually, the transformation of steel in ladle furnaces generates very significant volumes of by-products. At the same time, the physical-chemical process of anodization of aluminium surface generates metallic hydroxide sludges. One of the proposed solutions to minimise the landfilling of these by-products, and substitute it by a more environmentally friendly alternative, while also minimising the cost and energy required for the fabrication of Portland cement, is its application in the production of sustainable materials for the construction industry [16-18], or in several other different types of applications, like metallic elements immobilisation [19] or wastewater treatment [20,21]. In this paper, several of these wastes-Ladle slag, aluminium anodizing sludge, a recycled solution originally used to clean aluminium extrusion rods and phosphate sludge-were used to develop AAC pastes.

The application of ladle slag (LS) in alkaline activation reactions is somehow problematic, due to its essentially crystalline nature. Nevertheless, some studies were recently published that reported promising results. Adesanya et al. (2017) [22] studied the durability of ladle slag activated with potassium hydroxide and sodium silicate (a rare combination of the two elements), incorporating also different aggregate contents. After curing for $24 \mathrm{~h}$ at $60{ }^{\circ} \mathrm{C}$, the compressive strength reached 50 to $75 \mathrm{MPa}$ after 7 days, with subsequent strength reduction at the 28-day curing mark, followed by a second strength increase, between 28 and 56 days. This fluctuation was explained by the authors, as a consequence of the "... conversion of metastable reaction product to a stable one", a process similar to the hydration of calcium aluminate cement. The durability freeze-thaw tests indicated an improved response as the aggregate content in the paste increased, with strength reductions, after the freeze-thaw cycles, ranging from total failure (with no aggregate) to less than $1 \%$, with a sand-to-binder ratio of 1:6. Other authors obtained similar compressive strength values, 
using the same type of combined activator, and added fibrous reinforcement to mitigate the brittle behaviour evidenced in several studies [23]. The fibres not only transformed a 'brittle' behaviour into a 'ductile' behaviour, but they also help generate compressive strengths in excess of $90 \mathrm{MPa}$, without the need for increased curing temperature, which represents a significant performance improvement relatively to the $60{ }^{\circ} \mathrm{C}$-cured study. Another example of a promising result was obtained by Wang et al. (2016) [24], when activating LS with a $10 \mathrm{M}$ sodium hydroxide solution, with a constant $\mathrm{SiO}_{2} / \mathrm{Na}_{2} \mathrm{O}$ of 1 . The authors focused on mechanical and durability performance and concluded that an increase in the alkali agent is beneficial for both the mechanical and durability response, but detrimental for shrinkage, which was mitigated by curing under limewater.

The "World Aluminium" website reported a significant trend increase in the worldwide production of alumina (both metallurgical and chemical grade), which increased from 147,000 tons in 2000 to 367,000 tons, in 2020 [25]. The corresponding "aluminium anodizing sludge" (AS), generated during the anodization process, corresponds to approximately $47.5 \%$ [18], in weight, resulting in a variation between 70,000 tons (2000) and 174,000 tons (2020). Ribeiro and Labrincha (2008) [26] estimated a total of 100,000 tons a year, in 2008, in the EU space alone. Regardless of the large amount of AS produced worldwide, and the various constrains associated with its landfilling, there is currently limited knowledge regarding the application of these wastes in sustainable construction materials [27]. Nevertheless, significant efforts are being developed to look at new solutions for using AS in the production of sustainable construction materials, preferably with a significant mitigation of the calcination step. Mymrin et al. (2019) [27] combined three different industrial wastes to form water-based binders, namely AS microparticles (65-90\%), mortar wastes (0-15 wt.\%), and lime production wastes (5-20\%). The resulting compressive strength reached 2.5 to $11 \mathrm{MPa}$, which is an acceptable strength interval for some types of construction bricks. The authors also indicated that the use of AS microparticles can enhance the binding effect of the lime production waste, because of its high alkalinity and reactivity [18]. Onutai et al. (2015) [28] used aluminium hydroxide waste in the production of alkali activated fly ash-based materials. It was found that the influence of the aluminium hydroxide waste on mechanical strength depends on the sodium hydroxide concentration and curing regime. As aluminium waste could be a source of alumina, it could affect the condensation reaction to form Si-O and Al-O in alkali activated materials. The results indicated that a suitable geopolymer was obtained with an aluminium waste content of $40 \%$, which was then activated by a $10 \mathrm{M} \mathrm{NaOH}$ solution, cured at $80^{\circ} \mathrm{C}$. Aluminium anodising sludge was also used in geopolymers based on mine tailings, to improve the resulting mechanical strength [29]. The AS enhanced the geopolymerisation degree and rate, due to a decrease in the $\mathrm{Si} / \mathrm{Al}$ ratio, which was only possible given the free Al that could be introduced in the matrix, from the AS.

Generally, alkali activators are a combination of sodium hydroxide and sodium silicate, which are responsible for the economic and environmental drawbacks associated with alkaline activation [30]. Thus, some efforts are being made to develop more sustainable alternatives to these commercial reagents. Ogundiran et al. (2016) [31] used AS as an activator in alkali activated fly ash-based binders, as a substitute of commercial silicate solutions. It was observed that the use of AS produced the lowest mechanical strength $(35-75 \%)$ and longer setting time $(30-40 \times)$, when compared with the pastes fabricated with potassium silicate. Cristelo et al. (2019) [32] used the same recycled alkaline solution proposed in the present paper to activate a combination of waste glass and AS. Results showed that this solution, although presenting a lower $\mathrm{pH}$ than its initial condition, due to the several cleaning cycles to which it was submitted, was perfectly capable of activating the mentioned precursors, producing pastes with compressive strength values in excess of $8 \mathrm{MPa}$.

There are only a few studies focusing on the reuse of phosphate sludge (PS) in the production of sustainable construction materials. Most of these studies are mainly targeting the development of new treatment approaches for solidification/stabilization of stainless- 
steel PS, with some success. Gupta et al. (2019) [33] replaced 10\% of OPC with PS, finding that such replacement can increase the compressive strength, and that PS can be used in common applications such as pavement tiles. Muliawan and Astutiningsih (2018) [34] mixed PS with kaolin to fabricated ceramic bricks, obtaining compressive strengths in excess of $20 \mathrm{MPa}$ with a PS weight content $20 \%$, sintered at $1200^{\circ} \mathrm{C}$. PS has also been used a clinker additive [35]. Other applications in the construction industry include the inclusion of PS as an aggregate [36], or as an additive to reduce porosity of clay blocks [37].

The present study assessed the combination of ladle slag with AS and PS, in order to obtain suitable pastes, with the required mechanical performance, exclusively based on by-products from the steelmaking industry. The impact of different combined contents of AS and PS in alkali activated ladle slag cements was assessed, as well as the activation of these combined precursors with a disposed solution, originally used in the steelmaking industry to clean aluminium extrusion rods. The study considered both fresh and hardened state, and determined the setting time, heat of hydration and compressive strength. Moreover, microstructural and mineralogical characterisation (SEM/EDX, FTIR and XRD) allowed a deep understating of the role of each waste in the final products. The aim was the maximisation of the compressive strength, while also incorporating the maximum waste content.

\section{Experimental Plan}

\subsection{Materials}

The ladle furnace slag (LS) was recovered from the steel company Megasa, located in the north of Portugal, while the aluminium anodizing sludge (AS) and the iron phosphate sludge (PS) were recovered from an aluminium anodizing company and from a carbon steel wire plant, respectively.

Since both the AS and the PS are recovered in sludge form, incorporating significant water contents-ranging from 50 to $80 \%$, depending on the filtering and drying conditions in the plant - the raw materials were immediately dried upon arrival to the laboratory, followed by a thorough milling process, to increase their specific surface and, thus, improve their reactivity. The PS was crumbled in a mortar mixer, and then crushed by hand using a mortar and pestle until all particles achieved a diameter of $250 \mu \mathrm{m}$. The AS was milled in a ball mill for $1 \mathrm{~h}$, while the LS particles below $250 \mu \mathrm{m}$ were submitted to the same ball mill for $8 \mathrm{~h}$. Homogenisation of the dry materials blends was achieved in a vibratory disc mill, for $1 \mathrm{~min}$, at $1200 \mathrm{rpm}$. Specific gravities of 3.06, 2.27 and $2.66 \mathrm{~g} / \mathrm{cm}^{3}$ were obtained for the LS, AS and PS, respectively, using a Le Chatelier volumenometer [38].

The particle size distribution of the three residues, obtained by laser diffraction on a Coulter LS 130 (range between $0.05 \mathrm{~mm}$ and $880 \mathrm{~mm}$ ), is shown in Figure 1. Note the significantly high particle content under $32 \mu \mathrm{m}$, for all three materials- $88.6 \%$ (LS), 75.0\% (AS) and $93.2 \%$ (PS). The efficiency of the milling process on the LS is very clear, since the under $32 \mu \mathrm{m}$ particle content of the original residue (Figure 1) was just $47.4 \%$.

The composition of the raw materials, obtained by X-ray fluorescence (XRF), on a BRUKER S8 TIGER X-ray spectrometer, is presented in Table 1. The LS shows significant calcium oxide and silica contents, with an accumulated weight of $70 \%$. The AS is basically aluminium hydroxide (94\%), with a small percentage of sulphur trioxide $(3.0 \%)$ and sodium oxide $(2.4 \%)$. The PS is mostly phosphorous pentoxide and iron oxide (accumulated weight of $79 \%$ ), with traces of sodium (3.6\%) and calcium $(1.0 \%)$. The presence of all these oxides resulted in considering the potential combination of these materials as precursors in alkaline activation reactions. 

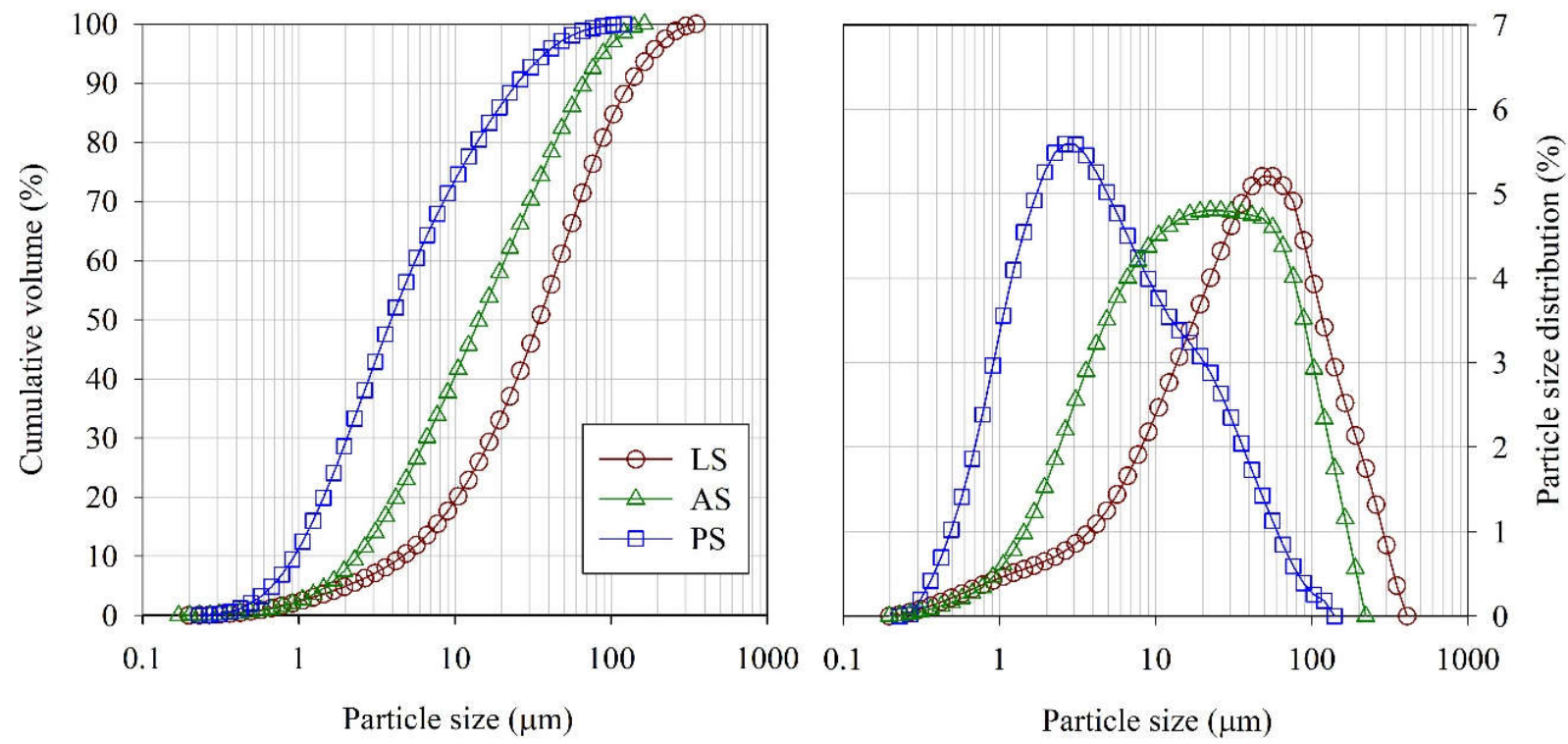

Figure 1. Particle size distribution of the milled LS, AS and PS.

Table 1. Chemical composition of the LS, AS and PS (\% wt.).

\begin{tabular}{cccc}
\hline Element & LS & AS & PS \\
\hline $\mathrm{Na}_{2} \mathrm{O}$ & 0.13 & 2.4 & 3.6 \\
$\mathrm{SiO}_{2}$ & 18.79 & 0.3 & - \\
$\mathrm{Al}_{2} \mathrm{O}_{3}$ & 7.39 & - & - \\
$\mathrm{Al}(\mathrm{OH})_{3}$ & - & 94.1 & - \\
$\mathrm{MgO}$ & 5.41 & - & - \\
$\mathrm{K}_{2} \mathrm{O}$ & 0.03 & - & 1.0 \\
$\mathrm{CaO}$ & 49.48 & - & - \\
$\mathrm{TiO}_{2}$ & 0.40 & - & 35.2 \\
$\mathrm{Fe}_{2} \mathrm{O}_{3}$ & 10.07 & - & 12.9 \\
$\mathrm{ZnO}$ & 1.25 & - & - \\
$\mathrm{MnO}$ & 1.43 & - & - \\
$\mathrm{BaO}$ & 0.10 & - & - \\
$\mathrm{P}_{2} \mathrm{O}_{5}$ & - & - & - \\
$\mathrm{SO}_{3}$ & 3.42 & 3.0 & 2.4 \\
$\mathrm{P}_{2} \mathrm{O}_{5}$ & 0.07 & - & - \\
$\mathrm{Cl}$ & 0.05 & - & - \\
$\mathrm{Cr}_{2} \mathrm{O}_{3}$ & 0.68 & - & - \\
$\mathrm{CuO}$ & 0.03 & - & - \\
\hline $\mathrm{F}$ & 1.20 & - & \\
\hline
\end{tabular}

Some chemical elements are essential to have polymerisation reactions in alkaliactivated reactions, namely aluminium, silicon, calcium and sodium. Based on the chemical compositions presented in Table 1, the LS is mainly rich in calcium species, while the AS is rich in aluminium, sulphur and sodium. Finally, the PS shows high contents of iron and phosphor. The AS and PS were added to the LS, as co-precursors, to compensate for its low content of $\mathrm{Al}$ and $\mathrm{Si}$ species. Therefore, different mass ratios of AS and PS were tested, as a partial replacement of the LS.

In terms of mineralogy (Figure 2), the LS presented calcium aluminosilicate and calcium sulphate as the main phases. The AS diffractogram revealed gibbsite as the only crystalline phase, while the PS main phase was phosphosiderite. 


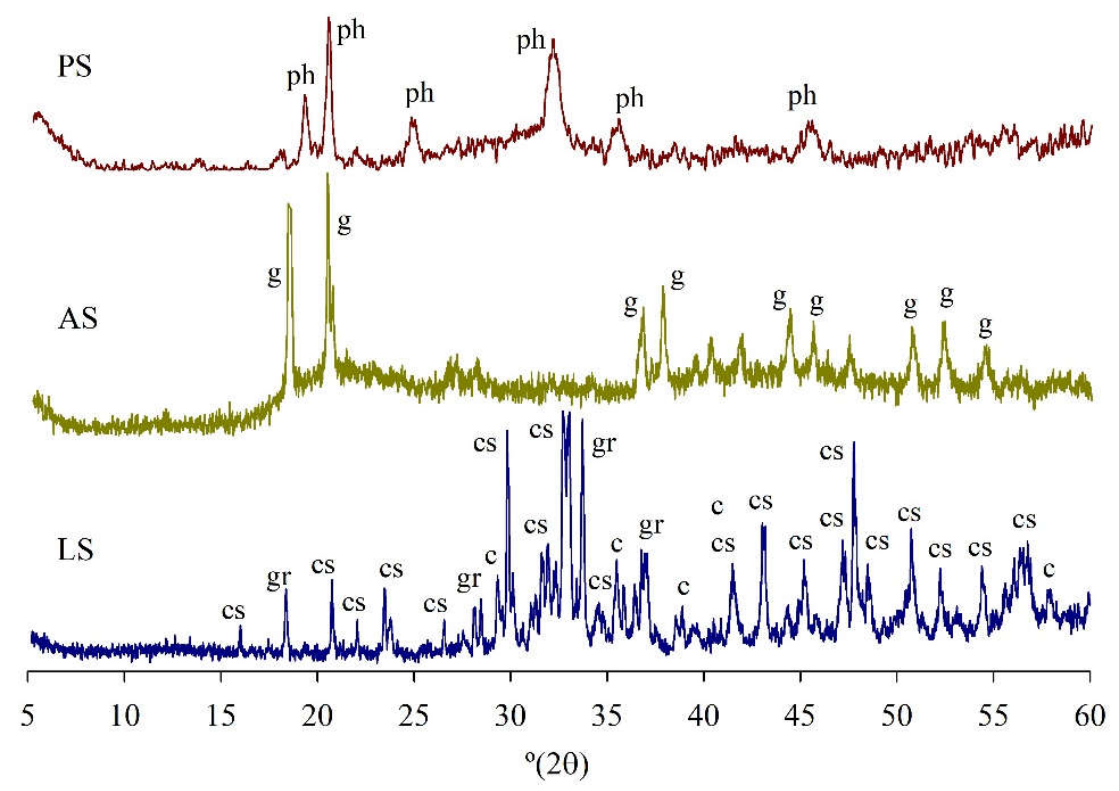

Figure 2. Predominant crystalline phases in the precursors: $\mathrm{c}=$ calcite $\left[\mathrm{CaCO}_{3}\right] ; \mathrm{cs}=$ calcium silicate $\left[\mathrm{Ca}_{6} \mathrm{O}_{4} \mathrm{Si}\right] ; \mathrm{g}=$ gibbsite $\left[\mathrm{Al}(\mathrm{OH})_{3}\right] ; \mathrm{gr}=$ grossular $\left[\mathrm{Ca}_{3} \mathrm{Al}_{2}\left(\mathrm{SiO}_{4}\right)_{3}\right] ; \mathrm{ph}=$ phosphosiderite $\left[\mathrm{Fe}_{3} \mathrm{PO}_{4}+\right.$ $\left.2\left(\mathrm{H}_{2} \mathrm{O}\right)\right]$.

Two different activators were used in this study: a 'commercial' solution (COM), combining sodium hydroxide (SH) and sodium silicate (SS), with an SH/SS weight ratio of 2 ; and a $\mathrm{NaOH}$-based solution originally used, by the Portuguese aluminium processing industry, to clean the aluminium extrusion dies. The latter will be hereafter referred as 'cleaning' solution (CLE) [32]. The sodium hydroxide pellets, with a specific gravity of 2.13 and $99 \mathrm{wt} . \%$ purity, were dissolved in distilled water to attain a $5 \mathrm{M}$ solution. The sodium silicate solution, with a specific weight of $1.464 \mathrm{~g} / \mathrm{cm}^{3}$ at $20^{\circ} \mathrm{C}$, was prepared with a $\mathrm{SiO}_{2} / \mathrm{Na}_{2} \mathrm{O}$ wt. ratio of 2.0 (i.e., a molar oxide ratio of 2.063) and a $\mathrm{Na}_{2} \mathrm{O}$ concentration of $13.0 \%$. The CLE solution presented a density of $1.25 \mathrm{~g} / \mathrm{cm}^{3}$, with $\mathrm{Na}$ and $\mathrm{Al}$ contents of $172 \mathrm{~g} / \mathrm{L}$ and $25 \mathrm{~g} / \mathrm{L}$, respectively. An acid-base titration, with $1 \mathrm{~N} \mathrm{HCl}$, revealed a sodium concentration slightly above $7 \mathrm{M}$ on the CLE, for an average $\mathrm{pH}$ of 13.9 .

\subsection{Preparation and Mechanical Testing}

The design of the experimental study was based on the pastes presented in Table 2. A total of eight formulations were defined, of which four were activated with the 'commercial' solution (COM), and the remaining four were activated with the 'cleaning' solution (CLE). The activator content of each paste was previously defined, based on trial and error to determine the minimum liquid phase required for proper homogenisation. Due to the different chemical and physical composition of each raw material, which resulted in different liquid requirements, it was not possible to adopt the same liquid content for each of the four pastes. Moreover, since the concentration of the two activators was also slightly different, the COM and CLE contents for the pastes with PS was not the same. 
Table 2. Composition of the pastes studied.

\begin{tabular}{ccccc}
\hline Paste ID & \multicolumn{2}{c}{ Precursors (Solids) } & $\begin{array}{c}\text { Activator/Solids } \\
\text { (A/S) }\end{array}$ \\
\hline & LS & AS & PS & (wt. Ratio) \\
\hline L-COM & $\mathbf{( w t . \% )}$ & $\mathbf{( w t . \% )}$ & $\mathbf{( w t . \% )}$ & 0.40 \\
LA-COM & 100 & 0 & 0 & 0.50 \\
LP-COM & 90 & 10 & 0 & 0.75 \\
LAP-COM & 90 & 0 & 10 & 0.55 \\
\hline L-CLE & 80 & 10 & 10 & 0.40 \\
LA-CLE & 100 & 0 & 0 & 0.50 \\
LP-CLE & 90 & 10 & 0 & 0.85 \\
LAP-CLE & 90 & 0 & 10 & 0.85 \\
\hline
\end{tabular}

The homogenisation of the pastes was performed with a benchtop drill press, coupled with a mixer blade. After mixing for $3 \mathrm{~min}$, the pastes were immediately submitted to mini-slump tests or casted in prismatic moulds with $1 \times 1 \times 6 \mathrm{~cm}$ (Figure 3a), and left to cure, at $25^{\circ} \mathrm{C}$ and $99 \%$ R.H. The removal from the moulds occurred 6 days after fabrication, while the uniaxial compressive strength testing (UCS) was performed after 7 and 28 days.

Mini-slump cone tests were performed to monitor the change in workability of the fresh pastes over time, following the contents of the ASTM C143. A conical mould is filled with paste and lifted quickly, allowing the paste to flow onto the table surface. The diameter of the spread paste is then measured along two perpendicular axes. It was noted that the pastes prepared with the COM activator showed a faster setting rate than those prepared with CLE. Furthermore, the incorporation of AS caused some delay of the setting time.

The mechanical performance was assessed on an IBERTEST AUTOTEST 200/10 SW servo-hydraulic testing machine. Uniaxial compressive strength (UCS) tests were carried out under monotonic displacement control, at a rate of $0.07 \mathrm{kN} / \mathrm{s}$. Each specimen was initially submitted to a flexural strength test, and the resulting halves were then submitted to compressive strength tests, as proposed by the ASTM D1633-17. Prior to testing, all specimens were measured and weighted. The UCS values presented in this work represent the arithmetic average of five tested specimens.

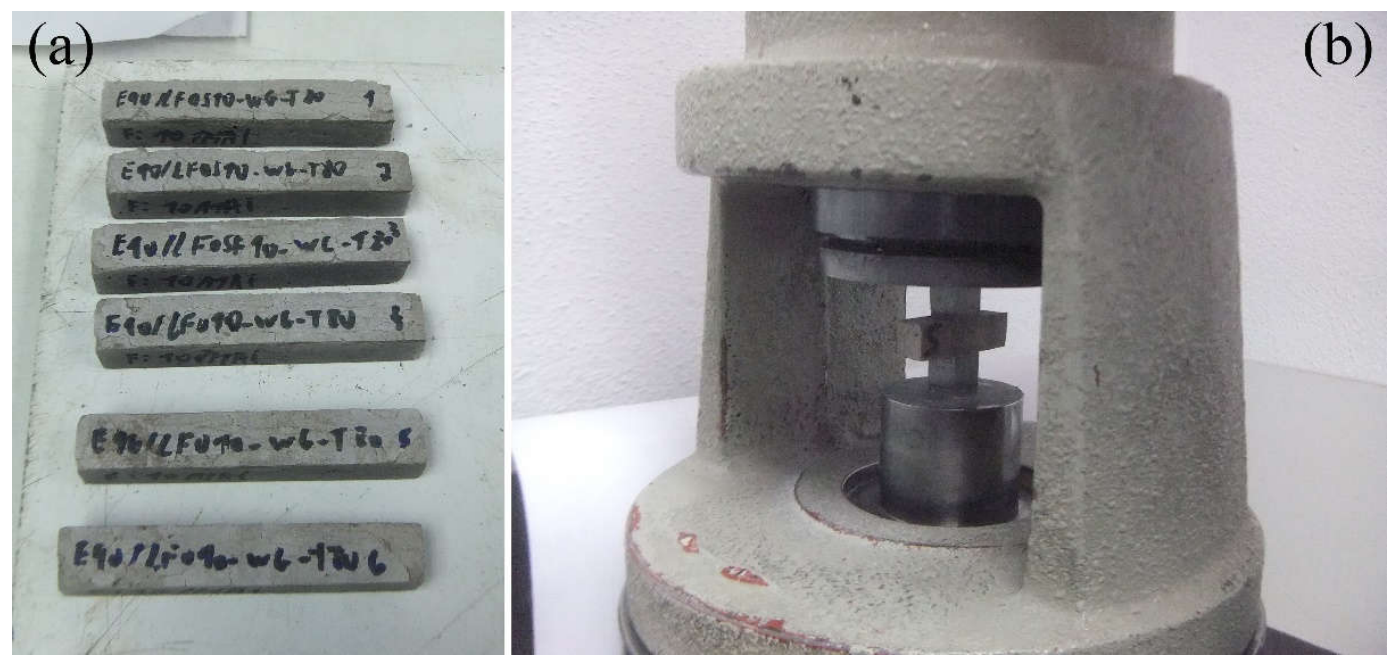

Figure 3. Prismatic specimens for mechanical testing (a) and compressive test of one of these specimens (b).

After the UCS tests, samples from each paste were ground, using a mortar and pestle, and frozen with an acetone/ethanol solution, to detain the chemical reactions. These samples were later submitted to X-ray diffraction (XRD) and observed by scanning electron microscopy (SEM), coupled with energy dispersive X-ray spectroscopy (EDX). 
The mineralogical analyses were carried out on a BRUKER D8 ADVANCE diffractometer, under $\mathrm{CuK} \alpha$ radiation $(40 \mathrm{kV}$ and $30 \mathrm{~mA})$, covering a 5-60 $2 \theta$ range with a nominal step size of $0.011973^{\circ}$ and $0.5 \mathrm{~s} /$ step. A Hitachi S-4800 scanning electron microscope $(20 \mathrm{kV})$, working in low vacuum mode (1.3 mbar) and fitted with an Oxford LINK-ISIS X-ray energy dispersive analyser (EDX), was used to perform the microstructural analyses.

Calorimetry tests were also performed, allowing the monitoring of the heat released throughout the reactions, using a TAM Air isothermal calorimeter, at a constant temperature of $25^{\circ} \mathrm{C}$. The samples were prepared according to the previously defined formulations presented in Table 2. The procedure to carry out the homogenisation of the samples was the same adopted to the preparation of the prismatic specimens (mixing time of $3 \mathrm{~min}$ using a benchtop drill press). The small containers used in the tests were sealed and placed in the calorimeter after being filled with the respective pastes.

\section{Results and Discussion}

\subsection{Workability}

The results of the mini-slump tests are shown in Figure 4. It is observed that the activator type has significant impact of the spread diameter (with differences of more than $50 \%$ ). Regarding the pastes L-COM and LA-COM, the spread values practically doubled, when compared to the L-CLE and LA-CLE counterparts, although the alkali activator/solid ratios are the similar or very close, in the case of pastes L, LA and LP.

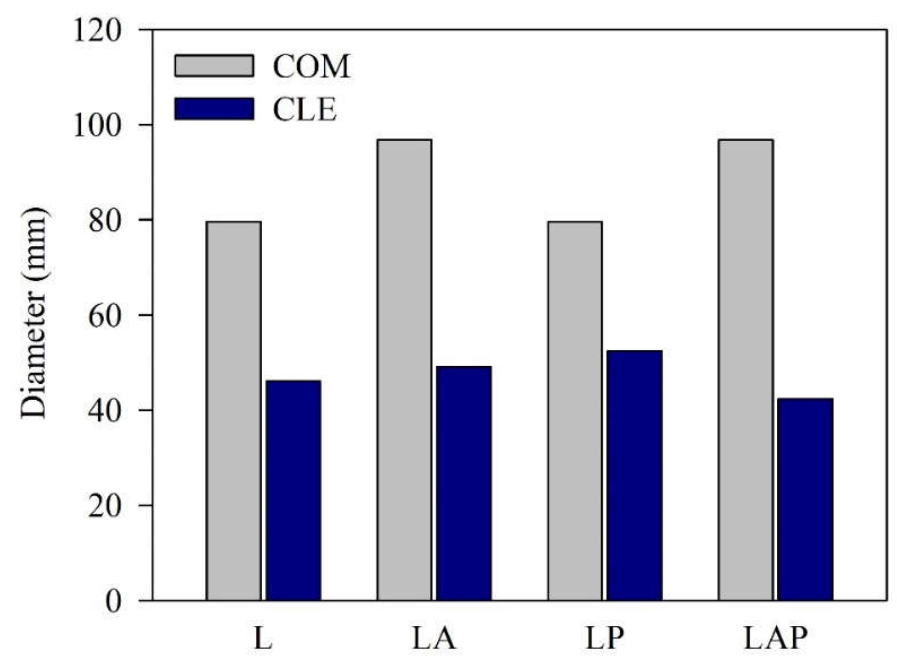

Figure 4. Mini-slump tests' results.

When COM was used as the activating solution, it is observed that the paste made exclusively from slag $(\mathrm{L}-\mathrm{COM})$, with a $\mathrm{A} / \mathrm{S}=0.40$, requires a considerably lower liquid phase to achieve a spreading value equal to that obtained for the paste $\mathrm{LP}-\mathrm{COM}(\mathrm{A} / \mathrm{S}=0.75)$, to which phosphate sludge was added. On the other hand, when comparing the pastes L-CLE $(\mathrm{A} / \mathrm{S}=0.40)$ and LP-CLE $(\mathrm{A} / \mathrm{S}=0.85)$, with CLE as the activating solution, different A/S ratios lead to similar spreading values.

The reason of these differences in spreading diameters come from mainly these two reasons: (1) Differences in size and geometric shapes of particles: Geometrical binder's shapes effect mainly on alkali demand, and angularity and surface roughness [39]. Moreover, angularity and surface roughness affect the interaction of particles, and this increases the internal friction. In general, regardless of alkali activator type, it seems that replacing LS with PS and AS enhanced the workability; (2) the properties of alkali activators: the molar ratio of $\mathrm{SiO}_{2} / \mathrm{Na}_{2} \mathrm{O}$ and the $\mathrm{Na}_{2} \mathrm{O}$ concentration of the activator are mainly responsible for fluidity in AAMs [40]. These two parameters affect the $\mathrm{pH}$ value and accelerates the dissolution of reactive silicates and aluminates, which it increases the viscosity and reduces the flowability. The sodium silicate solution is itself a solution of very high viscosity and 
an increase in its amount reduces the flow. Comparing CLE and COM indicates that alkali solution effected on dissolution of reactive silicates and aluminates.

In general, these results show that the nature of the precursors and the activators plays a decisive role with regard to the fluidity of the pastes that were analysed, and the considerable increase in the liquid phase does not necessarily lead to higher spreading values.

\subsection{Heat of Hydration}

\subsubsection{Pastes Fabricated with COM}

Figure 5 shows the accumulated heat and rate of heat release during the activation of AAMs with COM. The calorimetric responses show the existence of three peaks for pastes L-COM, LA-COM and LP-COM. The initial peak of great intensity attributed to mix L-COM, and another two peaks in compared to the first peak have considerably lower intensity and broader, which appears a few hours later. The presence of aluminium sludge and phosphate sludge in pastes LA-COM and LP-COM leads to a delay in the second reaction peak, which results in longer induction periods. On the other hand, the LAP-COM has a unique peak system with regard to the calorimetric response, which may be related to the presence of both additives of AS and PS. Considering the magnitude of the initial peaks of all pastes, it can be stated that the initial reactions are very fast (although the intensity of the peaks is different from paste to paste).
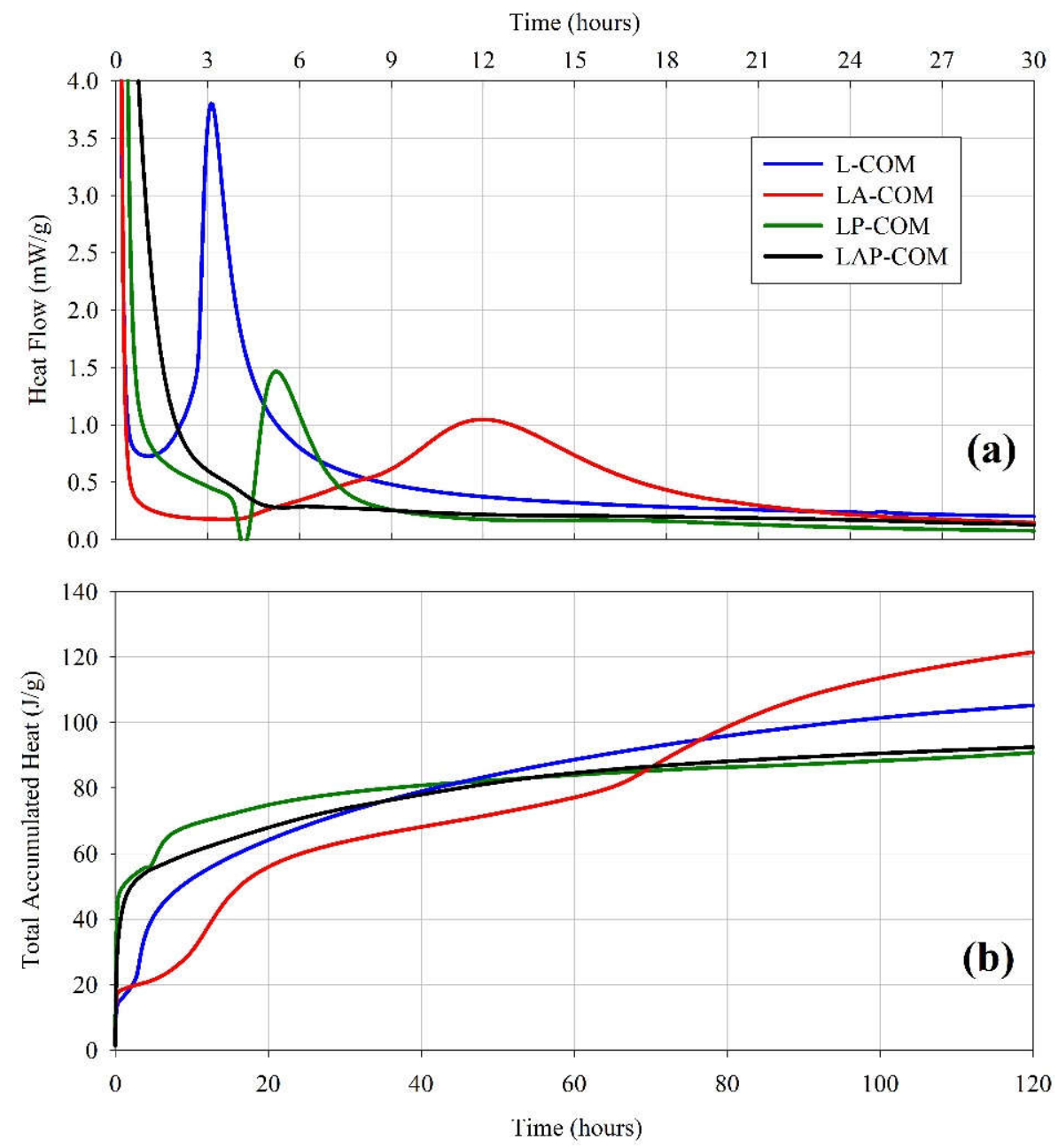

Figure 5. Heat of hydration of the pastes activated with COM-Heat Flow (a) and Total Accumulated Heat (b).

Regarding the accumulated heat curves (Figure 5b), it is observed that the degree of "hydration" in the long term, considering the analysed period, seems to be higher for 
L-COM, LP-COM and LAP-COM, in comparison with the LA-COM. The fact that the $\mathrm{LAP}-\mathrm{COM}$ presents a greater heat accumulated over time may be related to the higher $\mathrm{A} / \mathrm{S}$ ratio $(0.75)$.

The L-COM, LA-COM and LP-COM pastes presented accumulated heat curves with three distinct phases. The initial growth rate may be related to the dissolution of the slag particles, which is followed by a relatively "flat" phase, which concerns the induction period. The growth rate that appears after the induction period may be due to a phase of accelerated reactions (and formation of reaction products). The accumulated heat of the studied pastes, after $36 \mathrm{~h}$, is in the range $65-80 \mathrm{~J} / \mathrm{g}$.

\subsubsection{Pastes Fabricated with CLE}

Figure 6 shows the heat flow and the accumulated heat during the activation with CLE. Pastes LA-CLE, LP-CLE and LAP-CLE exhibit a calorimetric response with a single peak system, unlike the L-CLE (consisting exclusively of slag), which maintains a two-peak system. As with the L-CLE, the second acceleration peak in the L-CLE paste appears after $3 \mathrm{~h}$, although the intensity of this peak is significantly lower in this case. As can be seen, the use of this activator influences the kinetics of the reactions, especially for pastes that include co-binders, which exhibit only an initial peak of acceleration. This type of calorimetric response, in which only a single peak of great intensity is observed, suggests that it is at this stage that the main precipitations of the reaction products are generated. Similar to what was observed previously, for the CLE-activated pastes, the magnitude of the initial peaks of the COM-activated pastes suggests that the initial reactions are very fast (again, significant differences are found between the peak intensities).

Regarding the accumulated heat (Figure 6b), a similar trend to the LA-CLE paste is observed, which is the one that exhibits a lower degree of "hydration" in the long run. The L-CLE presents a curve of accumulated heat in which three distinct phases can be identified: increasing initial rhythm regarding the dissolution of the slag particles and a later increasing rhythm in which there is a phase acceleration of reactions (between the initial dissolution phase and the second acceleration rhythm the induction period appears).

The accumulated heat of the CLE-activated pastes, after $36 \mathrm{~h}$, is in the range $60-80 \mathrm{~J} / \mathrm{g}$, which is very close to the range verified for the pastes activated with COM $(65-80 \mathrm{~J} / \mathrm{g})$. This circumstance suggests that the degree of reaction of the pastes studied in the analysed period, regardless of the activator used, is similar.

\subsection{Uniaxial Compressive Strength}

Figure 7 shows the compressive strength after 7- and 28-days curing. The maximum UCS was registered by the L-COM paste (approximately $22 \mathrm{MPa}$ ), after $28 \mathrm{~d}$. This paste reached $50 \%$ of its final strength after 7 days, suggesting an early fast reaction rate. This trend (i.e., early strength gain) was observed for all pastes prepared with the COM activator, although it should be noted that the values shown by the LAP-COM paste are negligible when compared with the reference paste (L-COM), in which only LS was used. However, it should be noted that even lower strength AAMs can be used for non-structural applications [41].

Pastes activated with CLE showed a different behaviour from those fabricated with the commercial activator. Regardless of the fact that the COM activator produced the paste with the highest UCS (L-COM), it is significant that the substitution of the slag by AS and/or PS was less detrimental in the CLE system. Moreover, the LA-CLE reached a 28-day UCS even higher than the reference L-CLE, suggesting that the incorporation of the AS was effective, in terms of mechanical behaviour. 

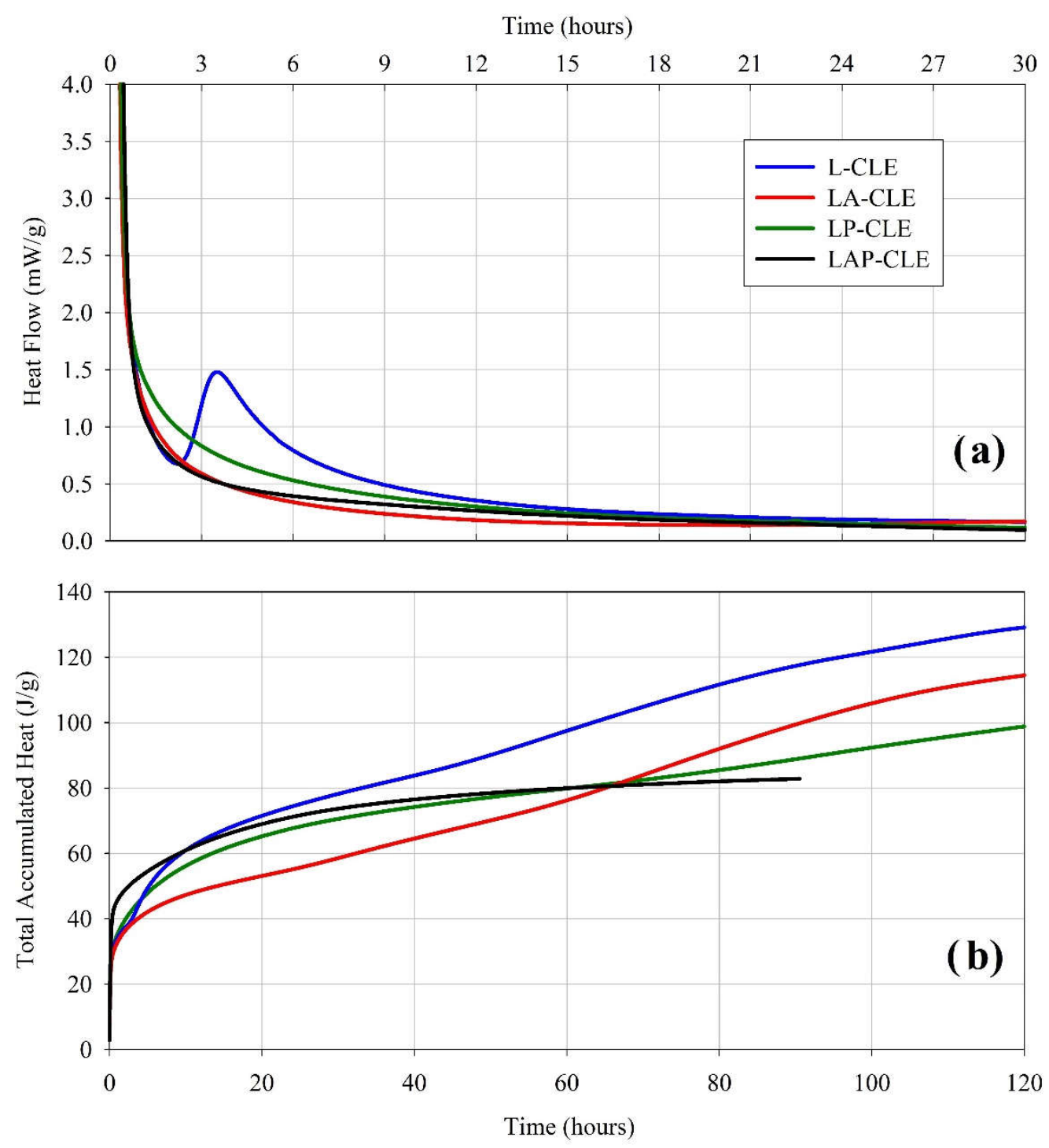

Figure 6. Heat of hydration of the pastes activated with CLE-Heat Flow (a) and Total Accumulated Heat (b).

Depending on the precursor combination, the 7 and 28 days UCS can be higher in the COM or CLE systems, depending on the precursor used. On the other hand, replacing the slag with either AS or PS required an increase in activator, which led to an increase in porosity and, subsequently, a decreased in strength. After 28 days, the maximum UCS in this study (obtained with the L-COM), was approximately 11 MPa higher than the most performing CLE-based paste (LA-CLE). However, replacing the slag by PS (instead of AS), although detrimental in both systems, was, nevertheless, more effective in the CLE than in the COM system.

Based on the compressive strength data, it is clear that different activators produced significant differences between the reference pastes (L-COM and L-CLE), of more than $6 \times$, after 7 days, and $2.5 \times$ after 28 days. Using different alkali activators affects the $\mathrm{OH}^{-1}$ concentration and, thus, the dissolution rate of the $\mathrm{Si}, \mathrm{Al}$ and $\mathrm{Ca}$ species and the ion-exchange required for new chemical reactions to occur. Therefore, it is expected that it affects more intensely the formation process of the C-A-S-H and C-(A)-S-H type gels [42]. The comparison between the compressive strength obtained during this study with data previously reported by Mymrin et al. (2018), which obtained UCS values between 2.5 and $11 \mathrm{MPa}$ when combining AS with construction and demolition waste and residues from the production of lime, indicates that the materials now developed are 
very competitive in terms of mechanical behaviour, with a high potential for different, non-structural applications.

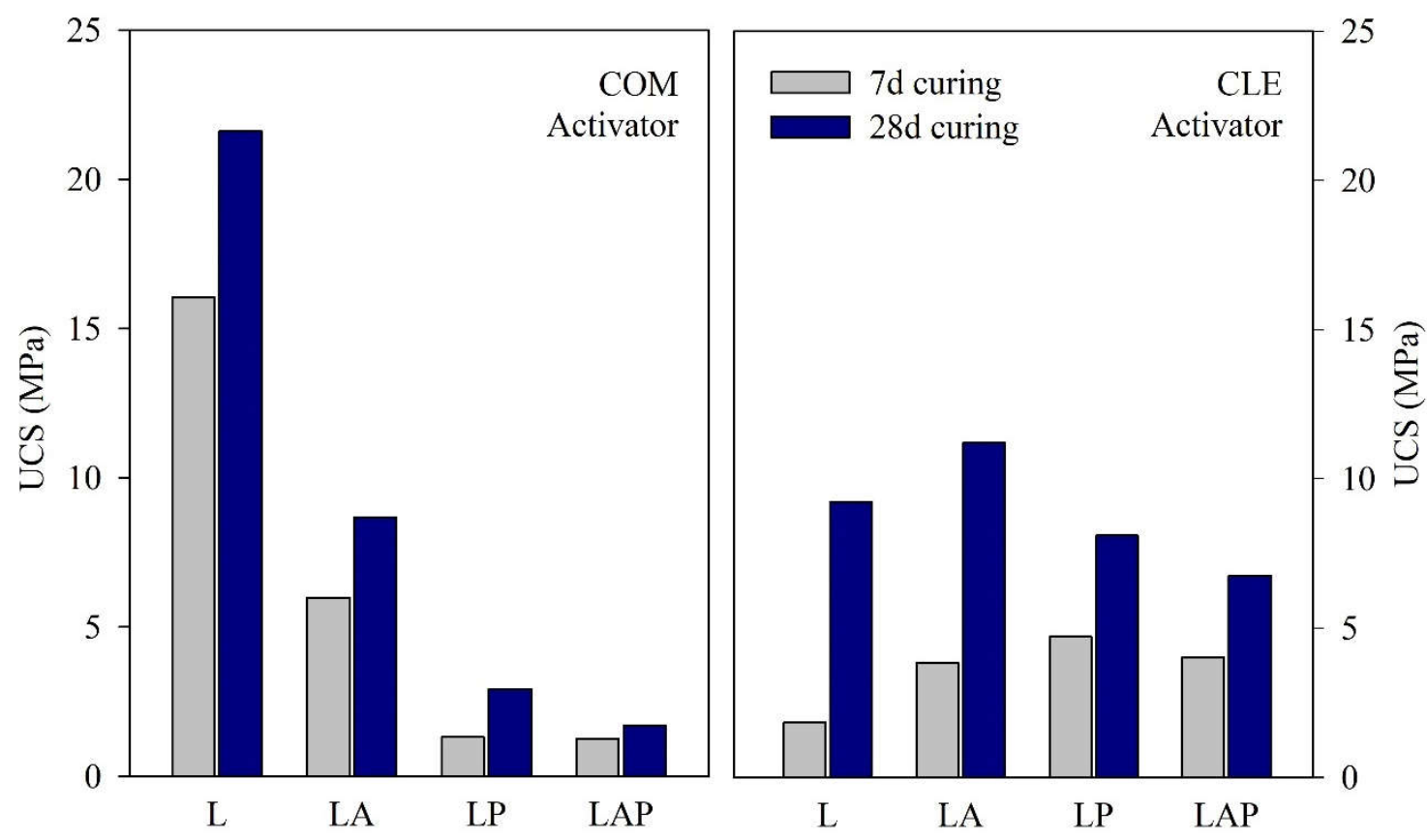

Figure 7. UCS of the pastes prepared with COM and CLE.

\subsection{Microstructure and Mineralogy \\ 3.4.1. SEM-EDX}

The SEM micrographs presented in Figure 8 reveal the general morphology of the pastes prepared with L, LA or LP, activated by COM or CLE, after 28 days curing. The combination with EDX analysis allowed to identify the main phases in the pastes, resulting from the combination of different precursors and alkali activators. The images are complemented with the gel composition of each paste (Table 3), characterised by the most influential atomic molar ratios obtained from the EDX average values of a minimum of 15 points.

Table 3. Atomic molar ratios of the gel phase of different pastes obtained from EDS analysis.

\begin{tabular}{|c|c|c|c|c|c|}
\hline \multirow[t]{2}{*}{ Paste ID } & \multicolumn{2}{|c|}{ Atomic Molar Ratios } & \multirow[b]{2}{*}{$\mathrm{CaO} / \mathrm{SiO}_{2}$} & \multirow[b]{2}{*}{$\mathrm{Na}_{2} \mathrm{O} / \mathrm{CaO}$} & \multirow[b]{2}{*}{$\mathrm{MgO} / \mathrm{Al}_{2} \mathrm{O}_{3}$} \\
\hline & $\mathrm{Al}_{2} \mathrm{O}_{3} / \mathrm{SiO}_{2}$ & $\mathrm{Al}_{2} \mathrm{O}_{3} / \mathrm{Na}_{2} \mathrm{O}$ & & & \\
\hline L-COM & 0.28 & 1.08 & 4.43 & 0.16 & 0.67 \\
\hline LA-COM & 0.63 & 4.25 & 3.47 & 0.19 & 0.18 \\
\hline LP-COM & 0.32 & 0.98 & 5.75 & 0.18 & 0.49 \\
\hline L-CLE & 0.21 & 1.67 & 4.79 & 0.07 & 0.48 \\
\hline LA-CLE & 0.40 & 1.79 & 2.85 & 0.19 & 0.26 \\
\hline LP-CLE & 0.21 & 0.42 & 2.67 & 0.31 & 0.50 \\
\hline
\end{tabular}

Differences in the $\mathrm{Al}_{2} \mathrm{O}_{3} / \mathrm{SiO}_{2}$ and $\mathrm{CaO} / \mathrm{SiO}_{2}$ molar ratios are mostly related with the precipitation, type of ion bonding and degree of condensation of the aluminosilicate structure in the gels. According to the morphology overview, using different alkali activators significantly changed the gel formation of the reference pastes. C-(A)-S-H and (C,N)-A-S-H were predominantly found in the L-COM system, while C-A-S-H gel was the main reaction product generated in the L-CLE. Differences in the gel formation (both in terms of quality and quantity) impacted the porosity of the matrix, which can help justify the differences registered in the mechanical strength. 

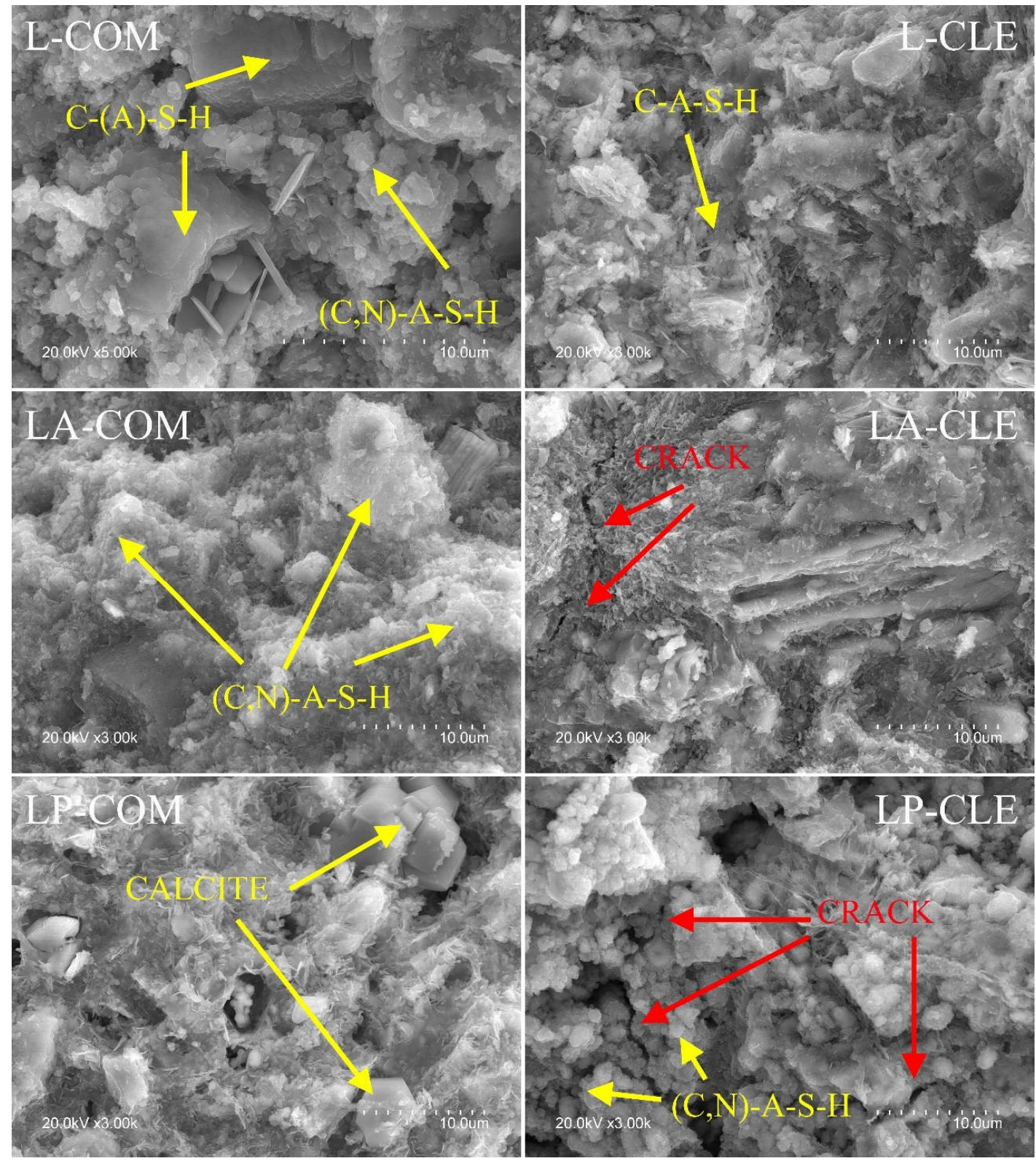

Figure 8. SEM images of selected pastes (L, LA and LP, activated with COM or CLE), after 28 days curing.

Regardless of the type of activator, and as expected, replacing the LA slag with AS increased the content of $\mathrm{Na}_{2} \mathrm{O}$ and $\mathrm{Al}_{2} \mathrm{O}_{3}$, and decrease the content of $\mathrm{SiO}_{2}$, relatively to the reference pastes (L-COM or L-CLE). The high aluminium oxide content of the AS, especially, showed a significant influence on the composition of the gel. As confirmed by the data presented in Table 3 , the molar ratios $\mathrm{Al}_{2} \mathrm{O}_{3} / \mathrm{SiO}_{2}, \mathrm{Al}_{2} \mathrm{O}_{3} / \mathrm{Na}_{2} \mathrm{O}$, and $\mathrm{Na}_{2} \mathrm{O} / \mathrm{CaO}$ increased due to the replacing of the LS with the AS. These ion exchanges influenced the formation of the respective gels, with (C,N)-A-S-H predominantly forming in the pastes with $10 \%$ AS (Figure 8 ). It was possible to observe the formation of some microcracks within the matrixes developed from the CLE activator, especially those including AS or PS.

Regarding the CLE systems, the partial substitution of LS by PS produced a relevant change in the morphology of the material, with an apparent reduction in porosity (which was probably responsible for the strength increase showed by this paste). This effect is possibly related with the increase in $\mathrm{Fe}_{2} \mathrm{O}_{3}$ and $\mathrm{P}_{2} \mathrm{O}_{5}$ content in the pastes, when the LS was replaced with the PS, which decreased the heat of hydration and, consequently, the 
mechanical strength [43], relatively to the reference (L-COM and L-CLE) and even, in the case of the cleaning solution systems, to the AS-based paste (LA-CLE).

\subsubsection{XRD}

A comparative XRD analysis was implemented to understand the impacts of using different types of alkali activators and different contents of AS and PS on the crystallized phases. The resulting x-ray diffractograms of the pastes are shown in Figure 9. The XRD showed that the newly formed crystalline phases of the pastes included gypsum, iron phosphate, calcium aluminate and thomsonite. The broad diffraction features of the major peaks mainly occurred at around $28^{\circ}-34^{\circ} 2 \theta$, around the trace of calcium silicate and calcite. Calcite is present in all the pastes, because of the slag [44], resulting from the carbonation of any remaining pore solution. Variations in the diffraction intensity of the calcite is due to the full removal of this pore solution (and the ions dissolved in it) by the solvent exchange. The diffraction peak belonging to both calcite and calcium silicate is identified at $29.5^{\circ} 2 \theta$, an angle which is usually assigned to calcium silicate hydrate gel, but it could not be well-defined due to its semi-crystalline nature [45]. In this study, the intensity or position of the diffraction peaks did not change significantly between the pastes containing PS or/and LS. The only difference between the PS and LS pastes is the presence of the zeolite-like thomsonite and the poorly crystalline C-A-S-H gel. The formation of these gels greatly affected the mechanical strength. These mineralogical results suggest that either the use of PS or/and AS or different alkali activators does not significantly change the crystallography of the pastes.
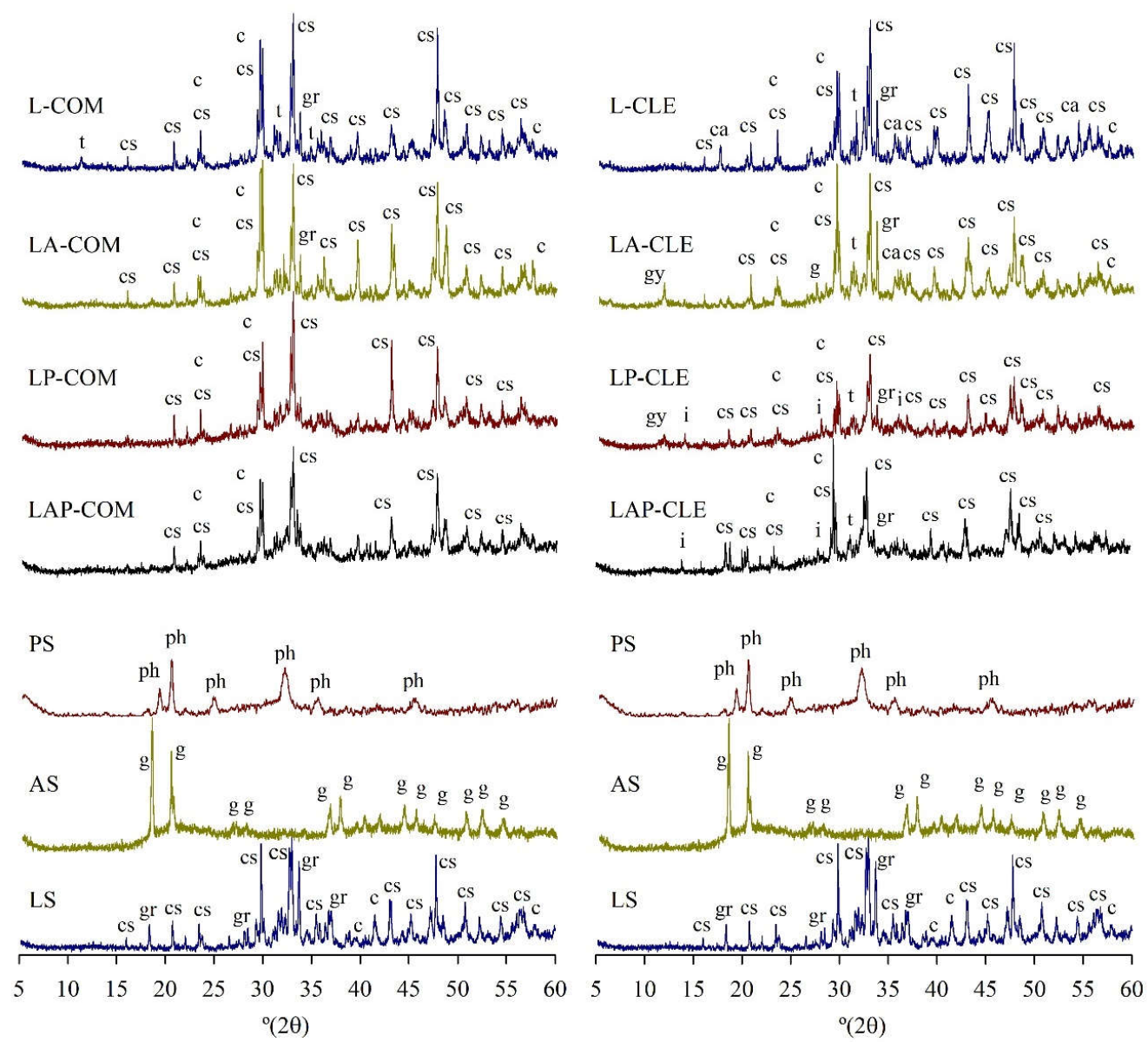

Figure 9. Predominant crystalline phases in the pastes after curing for 28 days: $\mathrm{c}=$ calcite $\left(\mathrm{CaCO}_{3}\right)$; $\mathrm{ca}=$ calcium aluminate $\left[\mathrm{CaAl}_{2} \mathrm{O}_{4}\right] ; \mathrm{cs}=$ calcium silicate $\left[\mathrm{Ca}_{6} \mathrm{O}_{4} \mathrm{Si}\right] ; \mathrm{g}=$ gibbsite $\left[\mathrm{Al}(\mathrm{OH})_{3}\right] ; \mathrm{gr}=$ grossular $\left[\mathrm{Ca}_{3} \mathrm{Al}_{2}\left(\mathrm{SiO}_{4}\right)_{3}\right] ;$ gy $=\operatorname{gypsum}[\mathrm{Ca}(\mathrm{SO} 4)+$ $\left.2\left(\mathrm{H}_{2} \mathrm{O}\right)\right] ; \mathrm{i}=$ iron phosphate $\left[\mathrm{FePO}_{4}\right] ; \mathrm{ph}=$ phosphosiderite $\left[\mathrm{Fe}_{3} \mathrm{PO}_{4}+2\left(\mathrm{H}_{2} \mathrm{O}\right)\right] ; \mathrm{t}=$ thomsonite $\left[\mathrm{NaCa}_{2} \mathrm{Al}_{5} \mathrm{Si}_{5} \mathrm{O}_{20}+6\left(\mathrm{H}_{2} \mathrm{O}\right)\right]$. 


\section{Conclusions}

This study aimed to investigate the feasibility of using two different wastes recovered from metallurgical industry in alkali activated ladle slag binders. In addition, two different activators were used to activate these alternative materials. This paper was carried out in multi-stages, including the clarification of different parameter impacts effects on the kinetic chemical reactions using calorimetric behaviour, flowability, mechanical strength and microscopic and mineralogical studies. According to the obtained results, the following remarks can be highlighted:

Regardless of the content of PS or AS, the COM-based pastes obtained higher fluidity than CLE $(\geq 40 \%)$.

1. A similar accumulated heat was obtained for the pastes activated by CLE (60-80 J/g) and COM $(65-80 \mathrm{~J} / \mathrm{g})$. This suggests that their degree of reaction is close.

2. The maximum compressive strength was recorded with the L-COM $(25 \mathrm{MPa})$. The replacement of the LS with AS and PS generally reduced the UCS in the pastes activated with COM, with the PS producing higher strength reductions than the AS. With curing time, there was a shift in the most performing pastes, with the maximum strength activated by the CLE-based formulations ( $5 \times$ higher than the COM pastes).

3. Using different alkali activators significantly changed the type of gel obtained with the reference pastes, resulting in a difference of approximately $16 \mathrm{MPa}$ between the L-COM and L-CLE pastes.

4. Replacing LS with AS or PS in the CLE systems resulted in microcracks in the matrix.

5. The mineralogical results showed that the use of PS or/and AS, or the different alkali activators did not significantly change the crystallography of the pastes.

Author Contributions: Conceptualization, N.C. and A.F.-J.; methodology, F.C. and A.F.-J.; validation, N.C., F.C. and T.M.; formal analysis, F.C. and A.F.-J.; investigation, N.C. and T.M.; resources, F.C.; data curation, A.F.-J.; writing—original draft preparation, Z.A.; writing—review and editing, N.C. and A.F.-J.; project administration, F.C.; funding acquisition, F.C. All authors have read and agreed to the published version of the manuscript.

Funding: This research has been financed by Geo-Design-Artifacts for hotels and urban furniture incorporating waste project, $\mathrm{n} .^{\circ}$ NORTE-01-0247-FEDER-017501, co-financed by the European Regional Development Fund (ERDF) through NORTE 2020 (North Regional Operational Program 2014/2020). The authors would also like to acknowledge the contribution of the Spanish Ministry of Science and Innovation and FEDER, for the funding through the PID2019-111464RB-100 project.

Conflicts of Interest: The authors declare no conflict of interest.

\section{References}

1. United Nations. Global Sustainable Development Report 2016 Edition; United Nations: New York, NY, USA, 2016.

2. Habert, G. Environmental impact of Portland cement production. In Eco-Efficient Concrete; Elsevier: Amsterdam, The Netherlands, 2013; pp. 3-25. [CrossRef]

3. Kurda, R.; Silvestre, J.D.; de Brito, J. Toxicity and environmental and economic performance of fly ash and recycled concrete aggregates use in concrete: A review. Heliyon 2018, 4, e00611. [CrossRef]

4. Naik, T.R. Sustainability of Concrete Construction. Pract. Period. Struct. Des. Constr. 2008, 13, 98-103. [CrossRef]

5. Verma, N.K. Influence of partial replacement of cement by industrial wastes on properties of concrete. In Lecture Notes in Civil Engineering. Springer Science and Business Media Deutschland GmbH; Springer: Singapore, 2021; pp. 693-713. [CrossRef]

6. Siddique, R.; Kaur, D. Properties of concrete containing ground granulated blast furnace slag (GGBFS) at elevated temperatures. J. Adv. Res. 2012, 3, 45-51. [CrossRef]

7. Sua-Iam, G.; Makul, N. Utilization of high volumes of unprocessed lignite-coal fly ash and rice husk ash in self-consolidating concrete. J. Clean. Prod. 2014, 78, 184-194. [CrossRef]

8. Serjun, V.Z.; Mladenovič, A.; Mirtič, B.; Meden, A.; Ščančar, J.; Milačič, R. Recycling of ladle slag in cement composites: Environmental impacts. Waste Manag. 2015, 43, 376-385. [CrossRef]

9. Najm, O.; El-Hassan, H.; El-Dieb, A. Ladle slag characteristics and use in mortar and concrete: A comprehensive review. J. Clean. Prod. 2021, 288, 125584. [CrossRef]

10. Kannan, D.M.; Aboubakr, S.H.; EL-Dieb, A.S.; Reda Taha, M.M. High performance concrete incorporating ceramic waste powder as large partial replacement of Portland cement. Constr. Build. Mater. 2017, 144, 35-41. [CrossRef] 
11. Provis, J.L.; Palomo, A.; Shi, C. Advances in understanding alkali-activated materials. Cem. Concr. Res. 2015, 78, 110-125. [CrossRef]

12. Provis, J.L. Alkali-activated materials. Cem. Concr. Res. 2018, 114, 40-48. [CrossRef]

13. Torres-Carrasco, M.; Rodríguez-Puertas, C.; Del Mar Alonso, M.; Puertas, F. Alkali activated slag cements using waste glass as alternative activators. Rheol. Behav. 2015, 54, 45-57.

14. Imtiaz, L.; Ur Rehman, S.K.; Memon, S.A.; Khan, M.K.; Javed, M.F. A review of recent developments and advances in eco-friendly geopolymer concrete. Appl. Sci. 2020, 10, 7838. [CrossRef]

15. Xie, J.; Chen, W.; Wang, J.; Fang, C.; Zhang, B.; Liu, F. Coupling effects of recycled aggregate and GGBS/metakaolin on physicochemical properties of geopolymer concrete. Constr. Build. Mater. 2019, 226, 345-359. [CrossRef]

16. Kaya-Özkiper, K.; Uzun, A.; Soyer-Uzun, S. Red mud- and metakaolin-based geopolymers for adsorption and photocatalytic degradation of methylene blue: Towards self-cleaning construction materials. J. Clean. Prod. 2021, 288, 125120. [CrossRef]

17. Nawaz, M.; Heitor, A.; Sivakumar, M. Geopolymers in construction-Recent developments. Constr. Build. Mater. 2020, 260, 120472. [CrossRef]

18. Mymrin, V.; Pedroso, D.E.; Pedroso, C.; Alekseev, K.; Avanci, M.A.; Winter, E.; Cechin, L.; Rolim, P.H.B.; Iarozinski, A.; Catai, R.E. Environmentally clean composites with hazardous aluminum anodizing sludge, concrete waste, and lime production waste. $J$. Clean. Prod. 2018, 174, 380-388. [CrossRef]

19. Taki, K.; Mukherjee, S.; Patel, A.K.; Kumar, M. Reappraisal review on geopolymer: A new era of aluminosilicate binder for metal immobilization. Environ. Nanotechnol. Monit. Manag. 2020, 14, 100345. [CrossRef]

20. El Alouani, M.; Saufi, H.; Moutaoukil, G.; Alehyen, S.; Nematollahi, B.; Belmaghraoui, W.; Taibi, M. Application of geopolymers for treatment of water contaminated with organic and inorganic pollutants: State-of-the-art review. J. Environ. Chem. Eng. 2021, 9 , 105095. [CrossRef]

21. Siyal, A.A.; Shamsuddin, M.R.; Khahro, S.H.; Low, A.; Ayoub, M. Optimization of synthesis of geopolymer adsorbent for the effective removal of anionic surfactant from aqueous solution. J. Environ. Chem. Eng. 2021, 9, 104949. [CrossRef]

22. Nguyen, H.; Adesanya, E.; Ohenoja, K.; Kriskova, L.; Pontikes, Y.; Kinnunen, P.; Illikainen, M. Byproduct-based ettringite binder-A synergy between ladle slag and gypsum. Constr. Build. Mater. 2019, 197, 143-151. [CrossRef]

23. Nguyen, H.; Carvelli, V.; Adesanya, E.; Kinnunen, P.; Illikainen, M. High performance cementitious composite from alkaliactivated ladle slag reinforced with polypropylene fibers. Cem. Concr. Compos. 2018, 90, 150-160. [CrossRef]

24. Wang, W.C.; Wang, H.Y.; Tsai, H.C. Study on engineering properties of alkali-activated ladle furnace slag geopolymer. Constr. Build. Mater. 2016, 123, 800-805. [CrossRef]

25. International Aluminium Institute World Aluminium: Primary Aluminium Production. Available online: https://www.worldaluminium.org/statistics / (accessed on 20 February 2021).

26. Ribeiro, M.J.; Labrincha, J.A. Properties of sintered mullite and cordierite pressed bodies manufactured using Al-rich anodising sludge. Ceram. Int. 2008, 34, 593-597. [CrossRef]

27. Mymrin, V.; Molinetti, A.; Alekseev, K.; Avanci, M.A.; Klitzke, W.; Silva, D.A.; Ferraz, F.A.; Iarozinski, N.A.; Catai, R.E. Characterization of construction materials on the base of mortar waste, activated by aluminum anodization sludge and lime production waste. Constr. Build. Mater. 2019, 212, 202-209. [CrossRef]

28. Onutai, S.; Jiemsirilers, S.; Thavorniti, P.; Kobayashi, T. Aluminium hydroxide waste based geopolymer composed of fly ash for sustainable cement materials. Constr. Build. Mater. 2015, 101, 298-308. [CrossRef]

29. Ren, X.; Zhang, L.; Ramey, D.; Waterman, B.; Ormsby, S. Utilization of aluminum sludge (AS) to enhance mine tailings-based geopolymer. J. Mater. Sci. 2015, 50, 1370-1381. [CrossRef]

30. Fernández-Jiménez, A.; Cristelo, N.; Miranda, T.; Palomo, Á. Sustainable alkali activated materials: Precursor and activator derived from industrial wastes. J. Clean. Prod. 2017, 162, 1200-1209. [CrossRef]

31. Ogundiran, M.B.; Nugteren, H.W.; Witkamp, G.J. Geopolymerisation of fly ashes with waste aluminium anodising etching solutions. J. Environ. Manag. 2016, 181, 118-123. [CrossRef] [PubMed]

32. Cristelo, N.; Fernández-Jiménez, A.; Castro, F.; Fernandes, L.; Tavares, P. Sustainable alkaline activation of fly ash, aluminium anodising sludge and glass powder blends with a recycled alkaline cleaning solution. Constr. Build. Mater. 2019, 204, 609-620. [CrossRef]

33. Gupta, R.; Singhal, A.; Devi, A.; Verma, S.K. A Study on Application of Pickling Sludge in Pavements Tiles. In Proceedings of the 3rd International Conference of Recent Trends in Environmental Science and Engineering (RTESE'19), Ottawa, ON, Canada, 11-12 June 2019. [CrossRef]

34. Muliawan, J.; Astutiningsih, S. Preparation and characterization of Phosphate-Sludge kaolin mixture for ceramics bricks. Int. J. Technol. 2018, 9, 317-324. [CrossRef]

35. Lin, K.L.; Lin, D.F.; Luo, H.L. Influence of phosphate of the waste sludge on the hydration characteristics of eco-cement. J. Hazard. Mater. 2009, 168, 1105-1110. [CrossRef]

36. Doğan, Ö.; Karpuzcu, M. Recovery of Phosphate Sludge as Concrete Supplementary Material. Clean-Soil Air Water 2010, 38, 977-980. [CrossRef] 
37. Bersch, R.; Brehm, F.; Kazmierczak, C. Changes in Ceramic Blocks Porosity with Phosphate Sludge due to Salt Crystallization WASCON 2012 towards Effective, Durable and Sustainable Production and Use of Alternative Materials in Construction; Swedish Geotechnical Institute and The International Society for the Environmental and Technical Implications of Construction with Alternative Materials: Gothenburg, Sweden, 2012.

38. UNE 80103 UNE 80103:2013-Metodos de Ensayo de Cementos. Ensayos físicos. Determinación de la densidade real. AENORAsoc. Española Norm. y Certificación 2013.

39. Pacheco-Torgal, F.; Castrogomes, J.; Jalali, S. Alkali-activated binders: A review. Part 2. About materials and binders manufacture. Constr. Build. Mater. 2008, 22, 1315-1322. [CrossRef]

40. Puertas, F.; Varga, C.; Alonso, M.M. Rheology of alkali-activated slag pastes. Effect of the nature and concentration of the activating solution. Cem. Concr. Compos. 2014, 53, 279-288. [CrossRef]

41. Achtemichuk, S.; Hubbard, J.; Sluce, R.; Shehata, M.H. The utilization of recycled concrete aggregate to produce controlled low-strength materials without using Portland cement. Cem. Concr. Compos. 2009, 31, 564-569. [CrossRef]

42. García-Lodeiro, I.; Palomo, A.; Fernández-Jiménez, A.; MacPhee, D.E. Compatibility studies between N-A-S-H and C-A-S-H gels. Study in the ternary diagram $\mathrm{Na}_{2} \mathrm{O}-\mathrm{CaO}-\mathrm{Al}_{2} \mathrm{O}_{3}-\mathrm{SiO}_{2}-\mathrm{H}_{2} \mathrm{O}$. Cem. Concr. Res. 2011, 41, 923-931. [CrossRef]

43. Chung, C.W.; Chun, J.; Wang, G.; Um, W. Effects of iron oxides on the rheological properties of cementitious slurry. Colloids Surfaces A Physicochem. Eng. Asp. 2014, 453, 94-100. [CrossRef]

44. Cao, R.; Zhang, S.; Banthia, N.; Zhang, Y.; Zhang, Z. Interpreting the early-age reaction process of alkali-activated slag by using combined embedded ultrasonic measurement, thermal analysis, XRD, FTIR and SEM. Compos. Part B Eng. 2020, 186, 107840. [CrossRef]

45. Richardson, I.G. The calcium silicate hydrates. Cem. Concr. Res. 2008, 38, 137-158. [CrossRef] 